\title{
EDITORIAL
}

\section{DÍVIDA PÚBLICA NO BRASIL: DIFERENTES MEDIDAS E SIGNIFICADOS}

\section{BRAZILIAN PUBLIC DEBT: DIFFERENT MEASURES AND MEANINGS}

José Roberto Afonso ${ }^{1}$

Não falta o que abordar em torno dos diferentes aspectos e questões que respeitam ao financiamento e ao gasto público na prestação de serviços públicos essenciais - como educação, saúde e segurança -, ou à concessão de benefícios - como os de previdência, assistência e proteção ao trabalhador. Apesar disso, em uma economia emergente, na qual seus governos gastam com o serviço de sua dívida um volume de recursos igual ou superior ao que se despende com muitos dos gastos sociais antes mencionados, nunca é demais conhecer e refletir sobre o citado endividamento governamental.

Voltando recentemente à berlinda no debate econômico brasileiro, a dívida pública teria saltado, no diagnóstico da situação atual, para seu ponto mais alto na história do Real. Nos exercícios perspectivos, crescem as preocupações com sua solvência, não se limitando às obras acadêmicas a exposição de sua situação crítica, uma vez que diversos veículos da mídia têm acompanhado os números e os problemas assim postos. Neste artigo, porém, não se trata desses valores e indicadores - nem do presente, nem do futuro. Antes de analisar os números, é preciso compreender o que representam - algo raro no debate brasileiro, a começar pelo fato de que são diferentes as medidas disponíveis para medir a dívida pública.

No lugar de apresentar e discutir os números dessa dívida no Brasil, é oportuno conhecer e refletir mais sobre a forma como ela é medida, sendo este, portanto, o objeto com o presente trabalho - antes um ensaio do que um artigo clássico.

No País, são adotadas diferentes metodologias para apurar o montante da dívida, nem sempre em linha com a teoria e as mais recorrentes práticas internacionais. Mudam desde o conceito do que seja dívida até a abrangência dos entes devedores, passando pelas diferentes fontes dos dados. Não é apenas uma questão de calcular de modo diferente, mas, também, de distinguir e refletir sobre o significado que está por trás de cada dívida pública.

Já existem várias contas, metodologias e documentos que medem e divulgam oficialmente quanto é a dívida pública brasileira. Os resultados são os mais discrepantes entre si, não apenas em termos de montante, mas também, recentemente, apontando tendências diferentes. Na época em que mais se questionaram práticas do Governo Federal para forjar resultados fiscais mais favoráveis,

\footnotetext{
Doutor em Desenvolvimento Econômico pela Universidade Estadual de Campinas; Mestre em Economia Industrial pela Universidade Federal do Rio de Janeiro; Professor do Programa de Mestrado no Instituto de Direito Público; Pesquisador no Instituto Brasileiro de Economia da Fundação Getúlio Vagas; SGAS II St. de Grandes Áreas Sul 607, 70200-670, Brasília, Distrito Federal, Brasil; zeroberto@joserobertoafonso.com.br
} 
alguns analistas passaram a defender outras formas de cálculo. Mais que isso, mesmo algumas autoridades econômicas passaram a questionar a forma como se media essa dívida pública fora do País, uma vez que adotado o mesmo método aqui resulta em um volume maior do que aquele que elas preferiam citar e adotar.

Depois de 2015, a mudança de governo e equipe econômica (mais de uma vez) fizeram tais questionamentos saírem do debate, embora as diferentes formas de medir a dívida pública tenham continuado exatamente as mesmas. Nada tendo mudado nas práticas oficiais, parece ter sido assumida a confiança de que se bastava mudar as pessoas para desaparecerem os problemas que as cercavam. É evidente que eles continuam postos e apenas se optou, por razões outras que não sejam da melhor técnica econômica, por ignorar ou postergar tais questões.

De certa forma, é possível dizer que imperou (e talvez ainda impere) uma prática pouco ortodoxa. Este seria o caso de inverter a ordem natural da investigação, para não dizer da matemática. Uma vez definidos inicialmente os resultados, a trajetória e a conclusão a que se deseja chegar, buscou-se uma fórmula de cálculo que atendesse àquela conveniência. A fundamentação lógica, o embasamento teórico e a experiência internacional se tornaram detalhes irrelevantes, considerados apenas se e quando pudessem levar à resposta predefinida. Tal prática foi tão mais acionada como mais os cenários prospectivos se tornaram mais incertos e sombrios.

Tradicionalmente, desde os anos 1980, a dívida pública no Brasil tem sido oficialmente medida pelo Banco Central do Brasil (BCB). ${ }^{2}$ Desde já, é curioso que não se questione no País o porquê de ainda ser a autoridade monetária a responsável por calcular os indicadores fiscais mais importantes e analisados, ao contrário do que ocorre na maioria das outras economias, avançadas e emergentes. Não se conhece outra economia com tal situação entre as maiores do mundo, em que o mais comum é que tal responsabilidade caiba ao Ministério da Fazenda ou das Finanças, quando não a algum órgão, por vezes colegiado, mas que esteja na esfera das autoridades econômicas e fazendárias - jamais uma autoridade monetária clássica.

O BCB divulga mensalmente três medidas da dívida pública. ${ }^{3}$ Duas delas, as chamadas dívida líquida e dívida bruta (em sua medida mais restrita), são informadas na chamada nota à imprensa de política fiscal. Outra medida da dívida bruta (justamente a que mais se aproxima do conceito usado internacionalmente), que o Banco Central chama de metodologia adotada até 2007, é publicada apenas no portal da internet, entre as séries temporais.

\footnotetext{
2 No portal na internet do Banco Central é possível encontrar uma página dedicada apenas à dívida pública em: Banco Central do Brasil (2017b). Sobre metodologia e processo de apuração e divulgação das contas, ver referências bibliográficas ao DEPEC.

3 O principal documento informativo do BCB sobre a matéria é uma nota mensal à (sic) imprensa sobre política fiscal, que reporta a dívida e o resultado fiscal, disponibilizada em: Banco Central do Brasil (2017a). Uma série histórica dos diferentes indicadores (pitorescamente, com mais dados do que aqueles inseridos na nota mensal antes citada) é divulgada pelo mesmo órgão em: Banco Central do Brasil (2017c).
} 
Até 2014 (e, sobretudo após 2008, quando Governo Federal passou a usar e abusar de medidas fiscais atípicas para gerar artificialmente resultados fiscais), ${ }_{4}^{4}$ praticamente o único conceito que era considerado nos documentos oficiais e também nas análises de mercado era a Dívida Líquida do Setor Público (DLSP). Resultava de uma subtração, em que se considerava tudo que é devido por conta de empréstimos tomados no sistema bancário e pela emissão de títulos, no mercado doméstico e no exterior, abatido de tudo que se tinha líquido, em caixa ou aplicado, e empréstimos concedidos. Por abrangência, são contadas as administrações públicas, direta e indireta, das três esferas de governo, além das empresas estatais - salvo as duas maiores empresas estatais: Petrobras e Eletrobras, excluídas da apuração do setor público desde $2009,{ }^{5}$ por decisão regulatória e não por razão econômica ou fiscal. ${ }^{6}$

Outra medida calculada é a Dívida Bruta do Governo Geral (DBGG). A diferença não corresponde apenas ao que se conta, mas também de quem se conta. Sendo bruta, conta somente o que se deve, na mesma forma antes medida, e são ignorados os haveres. Poucos atentam que muda também a abrangência (sendo bem menor nesse conceito) do mesmo adotado no resto do mundo: não são contadas as empresas e os bancos estatais e nem o Banco Central, pelo simples motivo de que não são entes governamentais no sentido clássico. Resultado disso é que passa a ser contado como dívida tudo aquilo que apenas as administrações públicas (direta ou descentralizada) devem, inclusive na forma de títulos que passem a constar na carteira das estatais e também do Banco Central (tratados da mesma forma que a dívida devida às empresas e aos bancos privados). Essa é a conceituação mais usada no exterior, tanto por organismos multilaterais, academia e agências de rating, quanto pelos órgãos dos outros governos que apuram seus indicadores oficiais.

Um dos aspectos comuns às três diferentes medidas de dívida do BCB está no fato de que são consolidados os débitos e os créditos entre as esferas e unidades do setor público abrangidas, não contando, portanto, para o resultado final, o que um ente público deve para outro ente. As dívidas renegociadas por governos estaduais e municipais e por empresas estatais no Tesouro Nacional, por exemplo, no caso da medida líquida, contam como dívida daqueles e são deduzidas da do Governo Federal, ou, no caso da medida bruta, simplesmente não são listadas entre as dívidas do chamado Governo Geral. Em outras palavras, é contado como dívida pública total apenas aquilo que é devido

\footnotetext{
4 O que aqui se propõe chamar engenharia fiscal no período citado foi criticada (ou denunciada), entre outros autores, por Afonso (2013), Barros e Afonso (2013) e Nobrega e Salto (2009).

5 Tal exclusão dessas empresas estatais das estatísticas fiscais foi objeto de duas decisões. Primeiro, a Petrobrás foi excluída definitivamente do contingenciamento de crédito pela Resolução n. 3647, de 26 de novembro de 2008, além de ter sido mudada a regra de exposição bancária pela Resolução n. 3.615 de 30 de setembro de 2008 (autorizou o BNDES a considerar cada uma das subsidiárias da Petrobras como um cliente distinto e não computar a participação do banco nas empresas para fins de cálculo da referida exposição). Com isso, o BCB republicou séries históricas sem a empresa retroagindo a dezembro de 2001 . A partir de outubro de 2010, o mesmo procedimento de exclusão foi aplicado à Eletrobras (Decreto n. 7.368 de 26 de novembro de 2010), tendo o BCB ajustado suas séries históricas desde dezembro de 2001.

6 O BCB assim justificou a exceção para a Petrobras: Foi dada a seguinte justificativa: "[...] se deve às características específicas da Empresa, uma das dez maiores do mundo na produção de petróleo, seguidora de regras de governança corporativa similares às experimentadas pelas empresas privadas de capital aberto, e com autonomia para captar recursos nos mercados interno e externo."
} 
ao resto da economia e não é somado aquilo que se deve de um para outro governo, de modo que sejam neutros no consolidado as dívidas e os créditos cruzados entre os governos.

Esse princípio correto não se aplica a uma exceção ou arbitrariedade. No cálculo oficial brasileiro da DBGG, ou seja, naquele indicador divulgado mensalmente na nota à imprensa, o órgão responsável, o BCB, arbitrou que, ao contrário do resto do mundo, não contaria como dívida do governo o que ele lhe deve em títulos de sua carteira. Ao invés de contar essa parcela de ativo do Banco Central, o próprio decidiu substituí-lo por uma parcela de seu ativo - as operações compromissadas, que são os empréstimos que o BC toma no mercado dando como garantia aquela carteira de títulos. As grandezas, porém, não são iguais. Aquela carteira sempre superou o volume de compromissadas porque o $\mathrm{BC}$ precisa de ativos que lhe rendam juros para que ele possa remunerar outros itens de seu passivo, como os recolhimentos compulsórios das instituições financeiras (que, no caso daqueles que não são à vista, o BC remunera até pela SELIC, ao contrário do resto do mundo) e os depósitos do próprio Tesouro Nacional (remunerado pela SELIC). Essa forma peculiar de medir a DBGG, aqui chamada de metodologia posterior a 2008, convencionou-se adotar como melhor medida da dívida, uma vez que não capta a chamada engenharia financeira e fiscal que autoridades fazendárias lançaram mão nos últimos anos para esconder parte do endividamento que patrocinavam.

À parte, vale comentar que mesmo a maior cobertura de passivos na DBGG do que na DLSP não garante uma visão plena e adequada. Os três indicadores oficiais de dívida pública apurados pelo Banco Central a subestimam, pois essa autoridade monetária não sabe quanto se deve para fora do sistema financeiro.

Assim, não é captado nessas contas, por exemplo, o que os governos devem: aos seus servidores, inclusive quando atrasam salários; aos empreiteiros e fornecedores de bens e serviços, por conta de contas a pagar; e aos credores de precatórios e agora também de depósitos judiciais, por conta de ações judiciais contra os governos. Não deve entrar na conta da dívida total (em face à já citada consolidação do setor público ou do governo geral), mas, se o objeto da atenção for o devido por uma esfera ou unidade de governo em particular, as medidas oficiais também deixam de contar como dívida de um governo aquilo que deixou de recolher em impostos e contribuições (inclusive previdenciária e FGTS) a outro governo.

O mais curioso (para não dizer incoerente, ou mesmo paradoxal) é que os citados passivos não identificados pelo BCB são escriturados e constam da contabilidade pública. Por princípio e por lei, devem constar nos balanços contábeis, oficial e regularmente divulgados, inclusive objeto da prestação anual e obrigatória de contas de cada governo. Isso para não falar que a mesma contabilidade fornece e alimenta os anexos de relatórios exigidos pela Lei de Responsabilidade Fiscal (LRF), como o quadrimestral Relatório de Gestão Fiscal (RGF).

Tudo isso é oficial e público, porém, sempre foi literalmente ignorado pelo órgão responsável pelo cálculo oficial e nacional da dívida pública. Pior, o mesmo desconhecimento também é contatado da parte dos analistas, do mercado financeiro à academia. Dos agentes públicos responsá- 
veis por formular e executar políticas, àqueles responsáveis por sua fiscalização e controle, inclusive externo, até aos próprios usuários fora do governo das suas estatísticas, raramente é manifestado conhecimento e muito menos feita alguma recomendação para que as dívidas contraídas pelos governos (mas não que não transitam pelo sistema bancário e pelo financeiro) também fossem contadas no total do endividamento do setor público ou do governo geral. Mesmo do Tribunal de Contas da União (TCU), que já dedicou muita atenção e investigação a tal dívida, é desconhecido que já tenha tomado alguma decisão mais contundente no sentido de cobrar uma revisão de práticas que venham a aumentar e tornar total e plena a cobertura dos débitos que contem como dívida do Governo Federal e mesmo do Nacional.

Nem na prática ou na regulação oficial, nem na cultura dos analistas, do mercado à academia, todos seguem acomodados ou, nas raras vezes que conhecem da falta de transparência, estão conformados com a rotineira e parcial mensuração da dívida, seja do setor público, seja do governo geral.

Além de serem parciais, as medidas tradicionais de dívida sofrem de outras distorções. Talvez a mais preocupante de todas é que, na medida oficial e mais usada que define a abrangência da DLSP, trata-se o BCB como parte integrante do setor público não financeiro. ${ }^{7}$ Por princípio (aliás, basta ler o nome do que seja o setor) e por prática internacional, o Banco Central não é um órgão que realize transações fiscais, que arrecade e gaste como um ente clássico de governo ou, como tal, endivide-se. Muito pelo contrário, o Banco Central é mais um e crucial financiador daquele governo. Afinal, esta é uma de suas funções intrínsecas, pois, ainda que central, ele é um banco não apenas na sua razão social, mas também em sua atividade, classificada notoria e internacionalmente como parte do sistema financeiro.

Parece que no Brasil se optou por levar ao limite máximo uma leitura jurídica, apegando-se à natureza jurídica da instituição: como o BCB é uma autarquia, ${ }^{8}$ a exemplo de uma universidade, de um hospital ou de uma unidade militar, o País segue levando ao pé da letra a exigência de que o Banco Central seja equiparado àquelas unidades de governo.

À parte a contradição conceitual, é curioso que a prática mudou, mas não para o caso do BCB. Afinal, a mesma leitura estreita não impediu de definir que as empresas Petrobras e Eletrobras, incluindo suas subsidiárias, não mais fossem tratadas e contadas como empresas estatais - ainda que, de direito, continuassem a ser como sempre foram. Isso, portanto, não resultou de uma mudança no marco legal ou de nova definição no conceitual econômico, mas, sim, de uma decisão

\footnotetext{
7 A abrangência das instituições financeiras oficiais no setor público é assim comentada em livro editado pela STN: "Contudo, os dados excluem as empresas estatais públicas financeiras (bancos), que são atores importantes do sistema financeiro brasileiro. Como as estatísticas fiscais visam principalmente a apurar o impacto das atividades do setor público sobre a demanda agregada, a exclusão das empresas financeiras deve-se às características próprias dessas empresas, que atuam como intermediárias financeiras e apresentam impacto macroeconômico diferenciado. Por sua vez, os dividendos pagos por elas ao setor público são incluídos no cálculo das necessidades de financiamento, bem como as despesas com eventuais aportes de recursos públicos para integralização de capital dessas empresas financeiras." (WEISMAN, 2009, p. 122).

8 Criado como autarquia desde sua criação pela Lei n. 4.595 de 1964.
} 
arbitrária: o governo queria liberar essas empresas para se endividarem e ampliarem investimentos visando combater à crise.

Para medir a dívida pública no País, se empresas estatais deixarão de ser contadas como empresas estatais, porque o BCB não pode passar a ser contado como uma instituição financeira, e isso o ser conceitual e formalmente?

Nesse contexto, revela-se mais uma jabuticaba com duplo fruto - fiscal e financeiro. $O$ Brasil é o único país do mundo em que o BCB faz parte do setor público para fins de calcular indicadores de resultado e de dívida. ${ }^{9}$ Em alguns raros países, como Nova Zelândia, é feita uma consolidação patrimonial de todos os balanços de todos os órgãos públicos, podendo ser contado o seu Banco Central, porém, é consolidada toda e qualquer forma de passivo e de ativo. Não parece, portanto, que daí decorram indicadores, práticas e políticas fiscais. O objetivo maior é a transparência fiscal.

Essa excentricidade conceitual e prática traz implicações cada vez mais sérias para a política econômica, tornando ainda mais intrincadas e incestuosas ${ }^{10}$ as relações entre a política fiscal e a monetária, cambial e creditícia. Era de se esperar que ao menos as autoridades econômicas (que sempre se dizem tão ciosas dos impactos fiscais sobre a política monetária), estivessem atentas aos resultados peculiares e excepcionais que resultam dessa excêntrica medida da dívida pública.

Causa espanto que se defenda para investidores no Brasil que a forma mais correta de avaliarem a dívida pública brasileira é descontando da dívida bruta o volume de reservas internacionais. Que leigos sobre as entranhas do cálculo de indicadores fiscais proponham cotejar alhos versus bugalhos pode-se relevar pelo desconhecimento - afinal, infelizmente, tais apurações seguem como uma "caixa-preta". A contabilidade pública, ignorada pela maioria dos economistas, torna-os livres para palpitar sobre o que não se conhece de direito e de fato.

É um erro crasso defender que se deva ler a dívida bruta deputada das divisas estrangeiras. Mesmo na medida realizada, mas escondida na divulgação, o Governo Geral (GG) da DBGG não inclui o BCB - ou seja, tal banco aparece como financiador daqueles governos. Ora, se a dívida do banco central não consta da dívida bruta, qual sentido matemático há em deduzir as reservas internacionais do mesmo banco central? Como um ativo que não pertence ao governo (mas, sim, ao banco central) deve ser abatido do que este deve?

Em termos jurídicos, é flagrante aberração supor que se pode pagar com reservas uma dívida vencida do governo, nem mesmo externa, quando mais em reais. As divisas internacionais não pertencem ao Tesouro, ainda que o banco central seja um órgão de Governo e nele aquelas sejam

\footnotetext{
9 A consolidação chamada de linha por linha das operações do Banco Central às do governo geral, como realizada no Brasil, é encontrada somente na Austrália e Nova Zelândia, segundo levantamento de Medas (s.d., p. 5) - mas é importante notar que aqueles países não centram a convenção da dívida em torno do conceito líquido como no caso brasileiro. $\bigcirc$ mesmo autor informa que algumas operações do Banco Central, em caráter parcial, são computadas nas contas fiscais na Bolívia, Peru, Uruguai e Filipinas (cada caso é um caso).

10 Delfim Netto (2016) também usou termo "relações incestuosas" para se referir as transações entre o Tesouro e suas empresas.
} 
depositadas, ele não pode as repassar para os cofres do Governo. Há uma independência determinada por mandamento legal.

Ora, as reservas atuais foram adquiridas pelo banco central, no caso brasileiro, basicamente com o setor privado (parcela mínima delas foram geradas ou recebidas pelos governos) e ainda estão depositadas no exterior. Em uma hipótese, que se espera jamais ocorra, que o Tesouro não disponha de caixa suficiente para pagar o serviço vincendo de sua dívida mobiliária, ele não pode simplesmente ir até o cofre do banco central e de lá sacar o volume de reservas que precisa para pagar sua dívida - quase toda em reais, mas mesmo em moeda.

Ora, o Tesouro Nacional não dispõe de uma espécie de cheque especial em dólares, em aberto, no Banco Central, para se financiar com ele. Muito menos o Banco Central pode ao seu bel prazer ou mesmo por ordem superior, trazer reservas do exterior, transformar em reais e depositar na conta do Tesouro, apenas para que eles paguem a quem deve.

A mera descrição dessas operações hipotéticas já revela o absurdo que suporiam, sendo curioso (e preocupante) como escapa às autoridades monetárias e mesmo aos analistas mais preparados o senso mais comum e, ainda mais, aspectos básicos do Direito. Se não há como autorizar legalmente que se faça tal tipo de operação financeira, por que se deve considerar, ainda que em uma leitura econômica, que as reservas internacionais sejam iguais às disponibilidades financeiras dos governos? Apenas pelo fato de ambos serem ativos e líquidos, não se autoriza que sejam tratados como iguais, uma vez que pertencem a proprietários diferentes: o ativo do Banco Central não pode se confundir com o ativo do Tesouro Nacional - aliás, quanto menos em sua lógica econômica, porque aquele é financiador deste.

À parte, é forçoso registrar que, não apenas nessas questões de dívida e divisas, em vários outros aspectos é pouco investigado e debatido o relacionamento econômico, financeiro e até mesmo legal entre Banco Central e Tesouro. Alcançam entre centenas de bilhões de reais as transações (fluxos) entre os dois órgãos (como venda e resgate de títulos, pagamentos de juros, transferências ou assunção resultados). Chega a passar da casa de trilhões de reais algumas posições patrimoniais entre os mesmos dois entes públicos (caso da carteira de títulos). Apesar disso, as relações entre Tesouro Nacional e Banco Central em nosso País raramente foram objeto de análise econômica, ${ }^{11}$ tanto menos de avaliações jurídicas. ${ }^{12}$

Ao invés de autoridades e analistas brasileiros gastarem esforços para tentar mais uma forma de medir e avaliar nossa dívida pública, poderiam fazer algo mais simples e que todo o resto do mundo já faz: excluir o Banco Central do setor público, quando apurada a DLSP, e computar toda a sua carteira de títulos, quando calculam a DBGG. Não há mais porque alegar que, sendo o Banco Central uma autarquia, ele não pode ser excluído do conjunto da administração pública indireta.

\footnotetext{
11 Talvez o único livro a tratar exclusivamente desse tema, com visões de diferentes autores e escolas econômicas, editado há pouco tempo tenha sido o livro editado pela Casa das Garças e organizado por Bacha (2017).

12 Uma rara abordagem, e recente, foi dada no artigo de Pinto, Pinto e Nascimento (2017).
} 
Ora, as próprias autoridades monetárias (por decisão do Conselho Monetário Nacional (CMN)) excluíram as empresas estatais e, de todo o setor público, os dois maiores de seus grupos empresariais. Aliás, analistas de mercado não reclamaram de tal prática nem incluíram tal exceção como uma das medidas atípicas. Isso significa que o Banco Central deve ser equiparado à forma como hoje já são tratados o Banco do Brasil, a Caixa e o BNDES: ainda que controlados pelo Estado, constituem financiadores dele e por isso não contados no setor público não financeiro.

É preciso, portanto, começar a seguir as práticas e os conceitos tradicionais e comuns ao resto do mundo. A dívida bruta é a melhor medida para avaliar a solvência do Governo e a dívida líquida; embora sinalize seu impacto para a economia, apenas o faz se mensuradas de forma a considerar apenas ativos financeiros e que realmente pertençam aos governos.

Já passa também da hora de adotar um limite para a dívida consolidada da União, já tendo o Executivo tomado iniciativa de propor o Executivo, desde 2000, e faltando o Senado exercer sua competência exclusiva. Isso completará a LRF (art. 30) e atenderá à inovação definida na Constituição de 1988 (arts. 48, XIV, e 52, VI). Fará com que o Governo Federal controle tal limite que, na era militar, estava imposto apenas aos governos estaduais e municipais - o que, na prática, continua valendo no País redemocratizado enquanto o Senado não se valer de sua competência.

Por último, não custa mencionar a posição mais atualizada dos indicadores aqui mencionados para ilustrar a importância desse debate e da regulamentação. Por mais que não sejam os dados em si o objeto desta breve análise, eles claramente ilustram a urgência necessária para que se conheça mais e, sobretudo, para que se possa finalmente regulamentar e aplicar os limites à dívida federal, inclusive para que seja dado o mesmo tratamento já dispensado aos governos estaduais e municipais.

O Gráfico 1 reproduz a evolução da dívida pública desde o início da década passada, nas três apurações oficiais realizadas pelo BCB e antes já comentadas neste ensaio. No longo prazo, é possível visualizar que as tendências são semelhantes, tanto na dívida líquida quanto nos dois conceitos da dívida bruta. 
Gráfico 1 - Dívida pública - diferentes medidas oficiais: 2001/2007 (em postos do PIB)

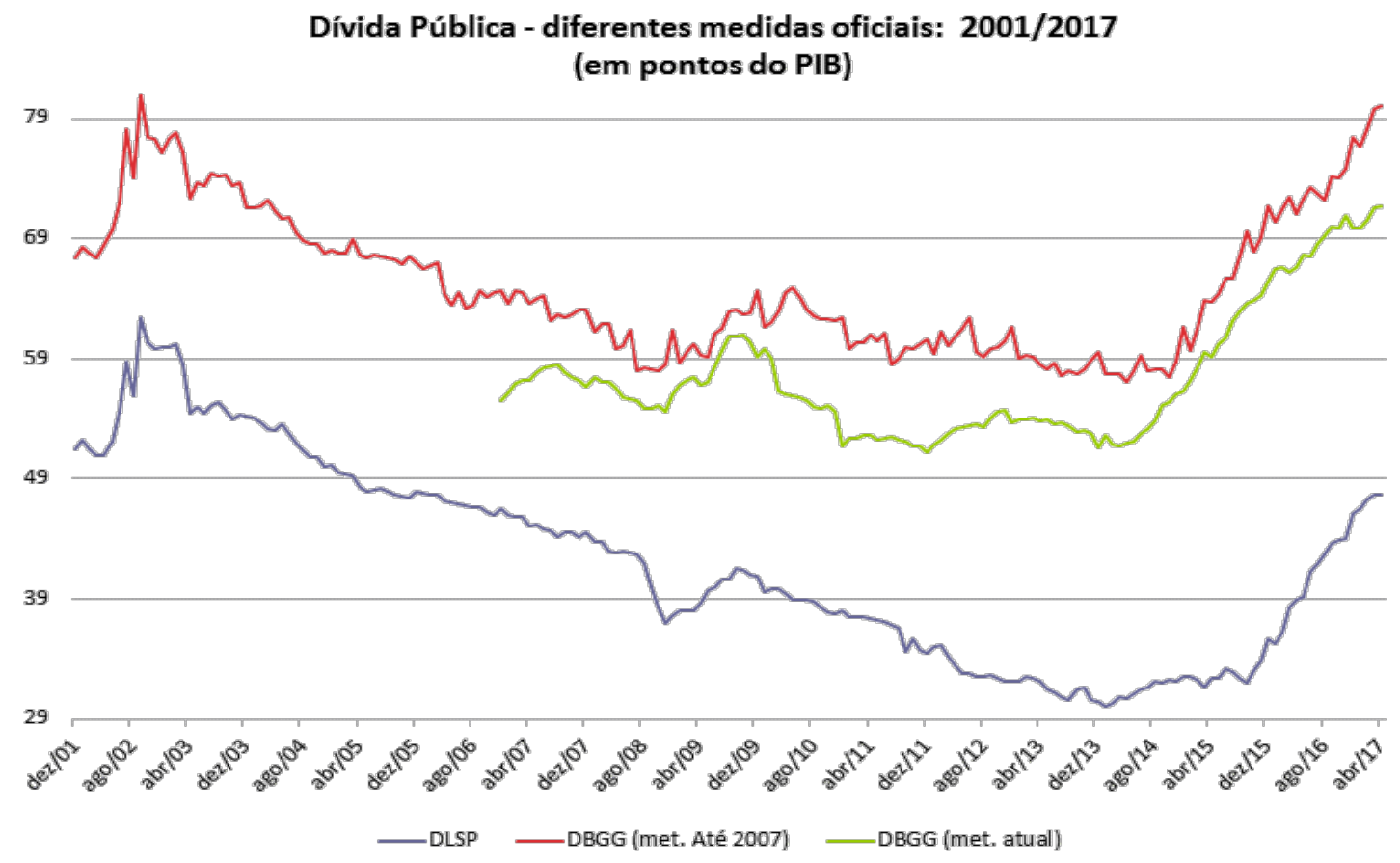

Fonte: os autores.

Ao final de abril de 2017, o total da DLSP ultrapassou os R 3 trilhões, ou 47.7\% do PIB. Na mesma data, já a DBGG na metodologia anterior a 2007 (ou seja, mais próxima da prática internacional) passou de R \$ 5 trilhões e bateu o recorde histórico ao cravar em 80\% do PIB (apenas em setembro de 2002, véspera da eleição nacional, que a mesma medida chegou a 81\%).

No conceito peculiar brasileiro de dívida bruta, a chamada DBGG na metodologia posterior a 2008 teve seu montante passando de $\mathrm{R} \$ 4,5$ trilhões e, também neste caso, batendo seu recorde de sua série histórica (que é mais curta), ao alcançar 71.7\% do PIB.

$\mathrm{Na}$ diferença entre os dois conceitos, destaca-se, no primeiro cálculo, a carteira de títulos do BCB superior a R\$ 1,6 trilhões, ou 25.6\% do PIB, que, no segundo cálculo, cai para um saldo de operações compromissadas próximo a R \$1,1 trilhão, ou 17.3\% do PIB, batendo, em ambos os casos, mais uma vez, recorde histórico.

Não custa relembrar que, muitas dívidas ditas forçadas, de curto prazo (como os restos a pagar) não estão contempladas nesses valores antes citados. Segundo a consolidação informada nos balanços de todos os governos brasileiros, publicada pela Secretaria do Tesouro Nacional (STN), para 2015 (último ano disponível), ${ }^{13}$ contado passivo de curto e de longo prazos, reportou-se: obrigações trabalhistas (inclusive salários), previdenciárias e assistenciais a pagar de R \$ 132 bilhões; os fornece-

$\overline{13}$ A consolidação é chamada de Balanço do Setor Público Nacional, e para o último exercício disponível, 2015, está disponível em Ministério da Fazenda e Secretaria do Tesouro Nacional (2016). 
dores e contas a pagar de R $\$ 81$ bilhões; e as obrigações fiscais de R \$ 3 bilhões - ou seja, somavam R \$ 216 bilhões. Apesar disso, os mesmos balanços ainda apontam, apenas no passivo circulante, demais obrigações na casa de R 234 bilhões.

Por si só, as citações das magnitudes dos volumes de recursos aqui citados e o fato de alcançaram os maiores patamares das séries históricas evidenciam a premência em se estudar mais as diferentes formas de apurar e contar o endividamento público no Brasil. Se fossem contados todos os compromissos assumidos pelo Poder Público e não limitados apenas àqueles contratados no sistema bancário, e se fosse privilegiado o controle da dívida bruta no lugar da líquida, não haveria estímulo para tanta engenharia fiscal, incluindo postergação de pagamentos ou realização destes por terceiros, como se verificou até 2014.

É hora de modernizar a mensuração da dívida pública e, por conseguinte, adotar em sua plenitude os limites e os controles previstos na Constituição e na Lei de Responsabilidade Fiscal.

\section{Referências}

AFONSO, José Roberto R. Transparência Fiscal no Brasil: convenções e conveniências. In: SANTI, Eurico et al (Org.). Transparência Fiscal e Desenvolvimento. São Paulo: Fiscosoft, 2013. p. 253-274.

BACHA, Edmar et al. (Org.). A Crise Fiscal e Monetária Brasileira. Rio de Janeiro: Civilização Brasileira, 2017.

BANCO CENTRAL DO BRASIL. Dívida pública. 2017a. Disponível em: < http://www.bcb.gov.br/ pt-br/\#!/n/DIVPUB > . Acesso em: 20 jun. 2017.

BANCO CENTRAL DO BRASIL. Notas econômico-financeiras para a imprensa.2017b. Disponível em: <http://www.bcb.gov.br/pt-br/\#!/n/ECOIMPRENSA>. Acesso em: 10 jun. 2017.

BANCO CENTRAL DO BRASIL. Séries temporais. 2017c. Disponível em: < http://www.bcb.gov. br/pt-br/\#!/n/SERIESTEMPORAIS > . Acesso em: 10 jun. 2017.

BARROS, Gabriel Leal de; AFONSO, José Roberto. Sobre "Fazer o Cumprimento" da Meta de Superávit Primário de 2012. Texto Para Discussão: IBRE/FGV, fev. 2013.

DELFIM NETTO, Antonio. E agora, o que fazer? Valor econômico, 17 maio 2016. Disponível em: <https://goo.gl/U9bnBy>. Acesso em: 20 jun. 2016.

DEPARTAMENTO ECONÔMICO. Dívida Líquida e Necessidade de Financiamento do Setor Público. Brasília: BCB, ago. 1999.

DEPARTAMENTO ECONÔMICO. Dívida Bruta do Governo Geral - Anexo. Nota para Imprensa sobre Política Fiscal. Brasília: BCB, fev. 2008.

DEPARTAMENTO ECONÔMICO. Finanças Públicas: Sumário dos Planos Brasileiros de Estabilização e Glossário de Instrumentos e Normas Relacionadas à Política Econômica-Financeira. 6. ed. Brasília, DF: Banco Central do Brasil, jun. 2008. Disponível em: <http://bit.ly/gxC6f7>. Acesso em: 30 set. 2010. 
DEPARTAMENTO ECONÔMICO. Manual de Estatísticas Fiscais. Brasília, DF: Banco Central do Brasil, jul. 2009. Disponível em: < http://bit.ly/blmTue>. Acesso em: 30 set. 2010.

NÓBREGA, Mailson da; SALTO, Felipe. Contabilidade criativa turva meta fiscal. O Estadão, São Paulo, nov. 2009. Disponível em: < http://www.estadao.com.br/noticias/geral,contabilidadecriativa-turva-meta-fiscal,474130>. Acesso em: 20 jun. 2017.

MEDAS, Paulo. How are central bank operations integrated in the fiscal accounts? Washington: IMF, s.d. Mimeografado.

MINISTÉRIO DA FAZENDA; SECRETARIA DO TESOURO NACIONAL. Balanço do Setor Público Nacional. Exercício de 2015. Brasília, DF, 2016. Disponível em: <http://bit.ly/2rRw7nz> . Acesso em: 20 jun. 2017.

PINTO, Élida Graziane; PINTO, Victor Carvalho; NASCIMENTO, Leandro Maciel do. LDO deve estimar riscos fiscais da relação entre Tesouro e Banco Central. Consultor Jurídico: Opinião, Rio de Janeiro, p. 1-2, jun. 2017. Disponível em: <http://www.conjur.com.br/2017-jun-16/opiniao-ldo-estimar-riscos-fiscais-relacao-entre-tesouro-bc>. Acesso em: 20 jun. 2017.

WEISMAN, Ethan. Referências internacionais e comparação com as estatísticas de dívida brasileira. In: SILVA, Anderson; CARVALHO, Lena; MEDEIROS, Otavio. Dívida Pública: a Experiência Brasileira. Brasília: STN, 2009. p. 117-128.

Data da submissão: 08 de agosto de 2017 Aceito em: 08 de agosto de 2017 
